\title{
Effects of ranitidine and cisapride on acid reflux and oesophageal motility in patients with reflux oesophagitis: a 24 hour ambulatory combined $\mathrm{pH}$ and manometry study
}

\author{
W Inauen, C Emde, B Weber, D Armstrong, H U Bettschen, T Huber, U Scheurer, A L Blum, \\ F Halter, H S Merki
}

\begin{abstract}
The effect of ranitidine and cisapride on acid reflux and oesophageal motility was investigated in 18 patients with endoscopically verified erosive reflux oesophagitis. Each patient was treated with placebo, ranitidine (150 $\mathrm{mg}$ twice daily), and ranitidine (150 $\mathrm{mg}$ twice daily) plus cisapride ( $20 \mathrm{mg}$ twice daily) in a double blind, double dummy, within subject, three way cross over design. Oesophageal acidity and motility were monitored under ambulatory conditions for 24 hours on the fourth day of treatment, after a wash out period of 10 days during which patients received only antacids for relief of symptoms. Acid reflux was monitored by a pH electrode located $5 \mathrm{~cm}$ above the lower oesophageal sphincter. Intraoesophageal pressure was simultaneously recorded from four transducers placed 20,15 , 10 , and $5 \mathrm{~cm}$ above the lower oesophageal sphincter. Upright reflux was three times higher than supine reflux (median (range) 13.3 $(3.7-35.0) \% v 3.7(0-37.6) \%$ of the time with $\mathrm{pH}<4.0, \mathrm{p}<0.01, \mathrm{n}=18$ ). Compared with placebo, ranitidine decreased total reflux (from $10.0(3.2-32.6) \%$ to $6.4(1.2-22.9) \%$, $p<0.01$ ), upright reflux $(p<0.05)$, supine reflux $(p<0.001)$, and postprandial reflux $(p<0.01)$, but did not affect oesophageal motility. The combination of ranitidine with cisapride further diminished the acid reflux found with ranitidine - that is, cisapride led to an additional reduction of total reflux (from 6.4 (1.2$22.9) \%$ to $3.7(1.0-12 \cdot 7) \%, p<0.01)$, supine reflux $(p<0.05)$, and postprandial reflux $(p<0.05)$. Cisapride also reduced both the number $(p<0.01)$ and duration $(p<0.05)$ of reflux episodes and significantly increased amplitude, duration, and propagation velocity of oesophageal contractions $(p<0.05)$ but did not affect the number of contractions. The findings show that the $30 \%$ reduction of oesophageal acid exposure achieved by a conventional dose of ranitidine (150 $\mathrm{mg}$ twice daily) can be improved to more than $60 \%$ by combination with cisapride ( $20 \mathrm{mg}$ twice daily). The cisapride induced increase in oesophageal contractile force and propagation velocity seems to enhance the clearance of gastrooesophageal reflux. Combination of a histamine $\mathrm{H}_{2}$ receptor antagonist with a prokinetic agent may therefore provide an alternative treatment for reflux oesophagitis.

(Gut 1993; 34: 1025-1031)
\end{abstract}

Several factors are responsible for recurrent exposure of the distal oesophagus to gastric contents and the subsequent development of reflux oesophagitis. ${ }^{1}$ Among these factors, a reduced basal tone ${ }^{2-7}$ and frequent episodes of inappropriate relaxation ${ }^{389}$ of the lower oesophageal sphincter are regarded as the most important. Other motor abnormalities of the oesophagus that may contribute to the development of reflux oesophagitis are diminished peristaltic pressure amplitude, ${ }^{4610}$ shortened duration and slowed propagation of the contraction waves, ${ }^{5}$ reduced peristaltic frequency, ${ }^{411}$ and delayed oesophageal transit. ${ }^{12}$ The importance of delayed gastric emptying in the pathogenesis of reflux oesophagitis is still controversial. ${ }^{13-18}$

Inhibition of gastric acid secretion has become the traditional medical treatment for reflux oesophagitis. The healing rates achieved by a six to eight week treatment of erosive reflux oesophagitis are about $50 \%$ for potent histamine $\mathrm{H}_{2}$ receptor antagonists (for example, ranitidine (150-300 mg twice daily $)^{19}$ ) and up to $90 \%$ for omeprazole, a proton pump inhibitor. ${ }^{2021}$ Although these drugs are effective, they do not reduce the reflux of other gastric contents (pepsin, bile) and they do not modify the underlying causes of the disease by restoring lower oesophageal sphincter pressure or improving oesophageal clearance and gastric emptying. The newest prokinetic agent, cisapride, a cholinomimetic drug, has been shown to improve function of the lower oesophageal sphincter and to improve oesophageal and gastric clearance. ${ }^{22}$ Also, cisapride produces healing rates of up to $50 \%$ in erosive oesophagitis that are comparable with histamine $\mathrm{H}_{2}$ receptor antagonists. ${ }^{23-28}$ As cisapride and histamine $\mathrm{H}_{2}$ receptor antagonists exert their effects by affecting different mechanisms, they may have an additive effect and produce higher healing rates than either medication alone. If this is the case, the combination of cisapride and ranitidine should produce a greater diminution in oesophageal exposure to acid than ranitidine alone.

This hypothesis was tested in patients with confirmed reflux oesophagitis by performing 24 hour ambulatory monitoring of intraoesophageal $\mathrm{pH}$ and pressure during treatment with placebo, ranitidine, and ranitidine combined with cisapride. The use of simultaneous 24 hour intraoesophageal $\mathrm{pH}$ measurement and four channel manometry, objective and highly reproducible 
techniques for assessing acid reflux and oesophageal motor function, ${ }^{29-33}$ allowed us to determine whether the effect of treatment on oesophageal $\mathrm{pH}$ was attributable to changes in oesophageal body motility.

\section{Patients and methods}

PATIENTS AND STUDY PROTOCOL

Nineteen patients enrolled into a study protocol approved by the ethics committee of the University of Bern, Switzerland. Each patient provided written consent after being fully informed about the study and the freedom to withdraw. The presence of reflux oesophagitis was confirmed by fibre endoscopy and classified according to Savary and Miller ${ }^{34}$ - namely, grade I (isolated erosions), grade II (linear confluent erosions), and grade III (circumferential erosions). Patients with reflux oesophagitis grade IV (oesophageal ulcer, Barrett's oesophagus, stenosis), concomitant gastrointestinal disease (active duodenal or gastric ulcer, pyloric stenosis, malignancy), other serious illnesses (cardiovascular, pulmonary, metabolic, hepatic, renal), intake of a proton pump inhibitor within the last four weeks, or intake of drugs affecting gastrointestinal motility were excluded from the study. The median (range) time interval between endoscopy and entering the study was $10(1-18)$ weeks. For control of reflux symptoms, the patients were allowed to take $\mathrm{H}_{2}$ receptor antagonists or antacids until 10 days before the start of the study after which they received only antacids.

From the 19 patients with reflux oesophagitis, one subject did not arrive for the second measurement and dropped out. In two subjects, the first combined $\mathrm{pH}$ and manometry recording was incomplete due to technical problems (failure of pressure recording). These patients were dropped from the study but were allowed to re-enter eight weeks later. Therefore, complete sets consisting of three combined 24 hour $\mathrm{pH}$ and manometry recordings were taken from 18 patients (17 men, one woman, median age 49.5 (range 31-72) years). From the 18 patients, three had the endoscopic diagnosis of reflux oesophagitis grade I, 12 patients had reflux oesophagitis grade II, and three patients presented with reflux oesophagitis grade III. No drug related adverse effects were found during and after completion of the study.

\section{STUDY DRUGS}

According to a double blind, double dummy, within subject, three way cross over design, patients were allocated to receive treatment with (a) placebo (one placebo tablet matching ranitidine and two placebo tablets matching cisapride twice daily), (b) ranitidine (one tablet ranitidine $(150 \mathrm{mg})$ and two placebo tablets matching cisapride twice daily), and (c) ranitidine plus cisapride (one tablet ranitidine $(150 \mathrm{mg}$ ) and two tablets cisapride $(10 \mathrm{mg})$ twice daily). The study drugs (three tablets each time) were ingested at 0915 (before breakfast) and 2200 (bedtime). Each treatment period lasted four days and the wash out periods before starting and during the study lasted 10 days. During the wash out period, the patients were allowed to take antacids (Maalox, Rorer GmbH, Bielefeld, Garmany) up to a maximum of two tablets four times a day, whereas during the treatment period, no drugs were taken except the study medication. Ranitidine (ranitidine hydrochloride, Zantac) and matching ranitidine placebo were provided by Glaxo Group Research, Greenford, United Kingdom. Cisapride (Prepulsid) and matching cisapride placebo was provided by Janssen Research Foundation, Beerse, Belgium. The treatment packs were prepared by Glaxo Group Research, Greenford, United Kingdom, in accordance with the randomisation code.

\section{STUDY DAYS}

Intraoesophageal $\mathrm{pH}$ and motility were investigated on day four of each treatment period. Patients attended the clinic at 0800 after an overnight fast. After local anaesthesia, two catheters (one for $\mathrm{pH}$, one for pressure recording) were inserted transnasally and their tips placed $5 \mathrm{~cm}$ above the lower oesophageal sphincter (described later). At 0900, continuous 24 hour recording of intraoesophageal $\mathrm{pH}$ and pressure was started. At 0915, all patients ingested their study medication and received a standard breakfast (bread, butter, marmalade, and coffee, tea, or milk). At 1200, a standardised lunch was served consisting of lasagna (baked layers of noodles, meat, cheese, and tomato sauce), bread, salad, and cake for dessert. At 1600 , the patients received a snack (tea or coffee with cake), and at 1800 , a standard dinner was served (Swiss style muesli, consisting of cereals, milk, yogurt, fresh fruits). Identical meals were prepared for each study day and they were eaten within 30 minutes of serving. Free access to water was allowed. Smoking was permitted but the number and timing of cigarettes were noted on a diary sheet and had to be similar on all study days. During the study days, the patients were fully ambulatory and could follow their preferred daily routine except that they had to return to the laboratory for their meals. After dinner, each patient returned home. The times of retiring and getting up on the next morning were noted on the diary sheet and marked electronically by pushing the appropriate buttons on the recording unit. At 0800 on the next morning, the patients returned to the laboratory and shortly after 0900 , the probes and recording equipment were removed.

PROBES AND PLACEMENT

A combined glass electrode (Ingold LOT 440-M4, Ingold Messtechnik AG, CH-8902 Urdorf, Switzerland) was used for intraoesophageal $\mathrm{pH}$ monitoring. Before and after each recording, the probe was standardised against buffer solutions at $\mathrm{pH} 1.7$ and $7 \cdot 0$. The drift found after the 24 hour measurement period never exceeded $0.2 \mathrm{pH}$ units. For intraoesophageal pressure monitoring, a catheter with four piezoresistive pressure transducers (Sentron, 9300 AC Roden, The Netherlands) mounted at the tip, and 5,10 , and $15 \mathrm{~cm}$ proximal to the tip 


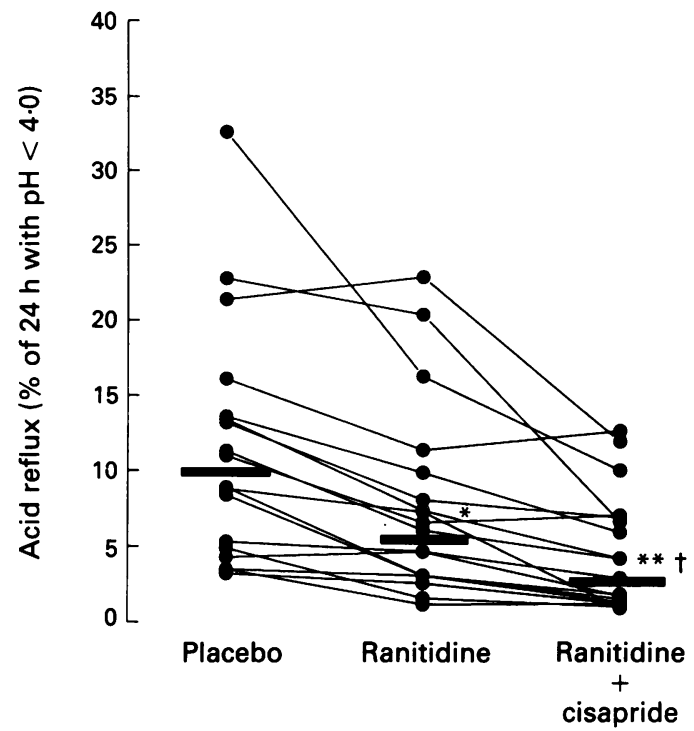

Figure 1: Oesophageal acid reflux (percentage of 24 hours with an intraoesophageal $p H<4 \cdot 0$ ). Horizontal bars indicate median; $n=18$ for all treatments. ${ }^{\star} p<0.01 ;{ }^{\star} p<0.001 \mathrm{v}$ placebo; $t p<0.01 \mathrm{v}$ ranitidine.

of the catheter were used. The pressure sensors were calibrated before and after each recording with mercury columns of zero and $250 \mathrm{~mm}$. There was no detectable drift of the pressure sensors after the 24 hour measurement period.

The two catheters were taped together and passed through the nose into the stomach. Throughout the insertion procedure, pressure and $\mathrm{pH}$ were displayed continuously on a computer monitor for identification of the lower oesophageal sphincter. The tips of both catheters were then placed $5 \mathrm{~cm}$ above the manometrically determined lower oesophageal sphincter and the probes taped to the nares, cheek, and neck. Based on the marks on the catheters, the distance between the tip of the probe and the nares was determined and an identical distance was used in subsequent measurements. Therefore, the $\mathrm{pH}$ recordings were taken from $5 \mathrm{~cm}$ above ${ }^{35}$ and intraoesophageal pressure monitored at 20, 15, 10 , and $5 \mathrm{~cm}$ above the lower oesophageal sphincter (four channel manometry).

\section{RECORDING DEVICE}

A portable eight channel datalogger (GastroScan II, Medical Instruments Corporation, $\mathrm{CH}-4502$ Solothurn, Switzerland) was used for ambulatory 24 hour recording of intraoesophageal $\mathrm{pH}$ and pressure. The data logger has three buttons to mark events (upright, supine, pain) and a liquid crystal display to check time and recorder function. The storage capacity of two megabytes random access memory allowed a sampling frequency of $5 \mathrm{~Hz}$ for each pressure sensor and $2 \cdot 5 \mathrm{~Hz}$ for the $\mathrm{pH}$ probe.

DATA ANALYSIS

For analysis of acid reflux and oesophageal motility, a software program running on IBM compatible computers was used (GastroScan Version 3.0, Medical Instruments, CH-4502 Solothurn, Switzerland). Comparison of the results obtained by this commercially available program with those obtained by a previously described and validated computer program ${ }^{29} 3233637$ showed good correlation.

To measure acid reflux, several parameters were used ${ }^{38}$ : (1) total reflux time ( $\mathrm{min}$ ), defined as the time with an intraoesophageal $\mathrm{pH}<4.0$; (2) total reflux time (\%), defined as the total time with an intraoesophageal $\mathrm{pH}<4.0$ expressed as a percentage of the analysed period; (3) reflux episodes $>6 \mathrm{~s}$, defined as the number of episodes with an intraoesophageal $\mathrm{pH}<4.0$ lasting longer than $6 \mathrm{~s}$; (4) reflux episodes $>5 \mathrm{~min}$, defined as the number of episodes with an intraoesophageal $\mathrm{pH}<4.0$ lasting longer than $5 \mathrm{~min}$; (5) mean reflux duration (min), defined as the mean duration of all reflux episodes; (6) maximal reflux duration ( $\mathrm{min})$, defined as the longest single reflux episode.

To measure oesophageal body motility, variables measured were ${ }^{32}$ : (1) amplitude of contraction $(\mathrm{mm} \mathrm{Hg})$, defined as the difference between the baseline pressure and the maximal pressure during the pressure event; (2) duration of contraction (s), defined as the time elapsed between
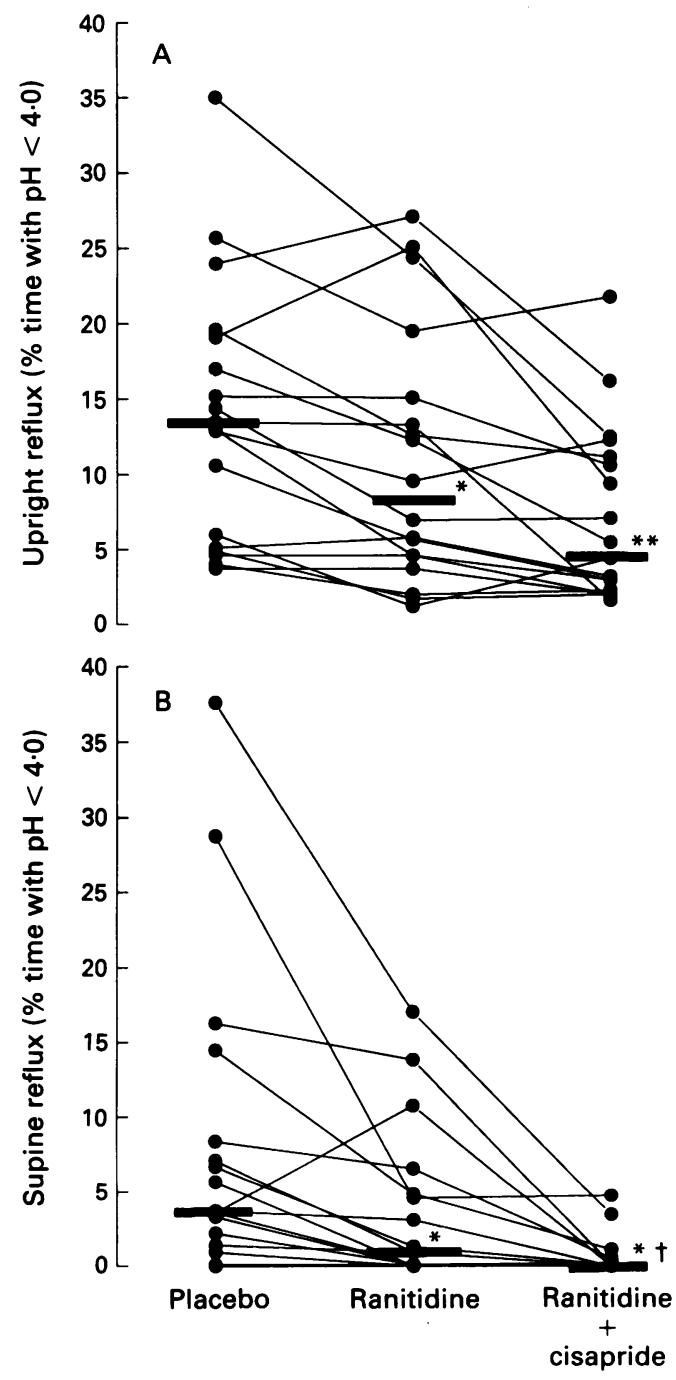

Figure 2: (A) Upright acid reflux (\% of time with an intraoesophageal $\mathrm{pH}<4 \cdot 0$ ). Horizontal bars indicate median; $n=18$ for all treatments. ${ }^{\star} p<0.05 ; \star \star p<0.001 \mathrm{v}$ placebo. $(B)$ Supine acid reflux (\% of time with an intraoesophageal $\mathrm{pH}<4 \cdot 0$ ). Horizontal bars indicate median; $n=18$ for all treatments. ${ }^{\star} p<0.001 \mathrm{v}$ placebo; $t p<0.05 \mathrm{v}$ ranitidine. 
the start and the end of the pressure event; (3) area under the pressure curve $(\mathrm{mm} \mathrm{Hg} \times \mathrm{s})$, calculated from the sum of all pressure values between the start and the end of the pressure event, multiplied by the sampling interval; (4) propagation velocity $(\mathrm{cm} / \mathrm{s})$, defined as the speed of a contraction and calculated from the delay time and the distance between the sensors; (5) contractility ( $\mathrm{mm} \mathrm{Hg} / \mathrm{s}$ ), defined as the maximal increment between consecutive pressure values divided by the sampling interval; (6) total contractions (no/24 h), defined as pressure curves that are not rejected as artifacts; (7) propagated contractions (no/24 h), defined as contractions that are detected by a proximal pressure transducer and followed by a contraction at the distal sensor. Propagation velocity had to be neither more than $8.3 \mathrm{~cm} / \mathrm{s}$ nor less than $1 \mathrm{~cm} / \mathrm{s} ;(8)$ nonpropagated contractions (no/24 h), defined as contraction waves that are not associated with a proximal contraction wave or have an apparent propagation velocity $>8.3 \mathrm{~cm} / \mathrm{s}$.

Several periods of interest were defined before analysis - namely, $24 \mathrm{~h}$, upright, supine, postprandial breakfast (0945-1145), postprandial lunch (1230-1430), and postprandial dinner (1830-2030).

TABLE I Oesophageal acid reflux (defined as intraoesophageal $p H<4 \cdot 0$ ) in 18 patients with erosive reflux oesophagitis

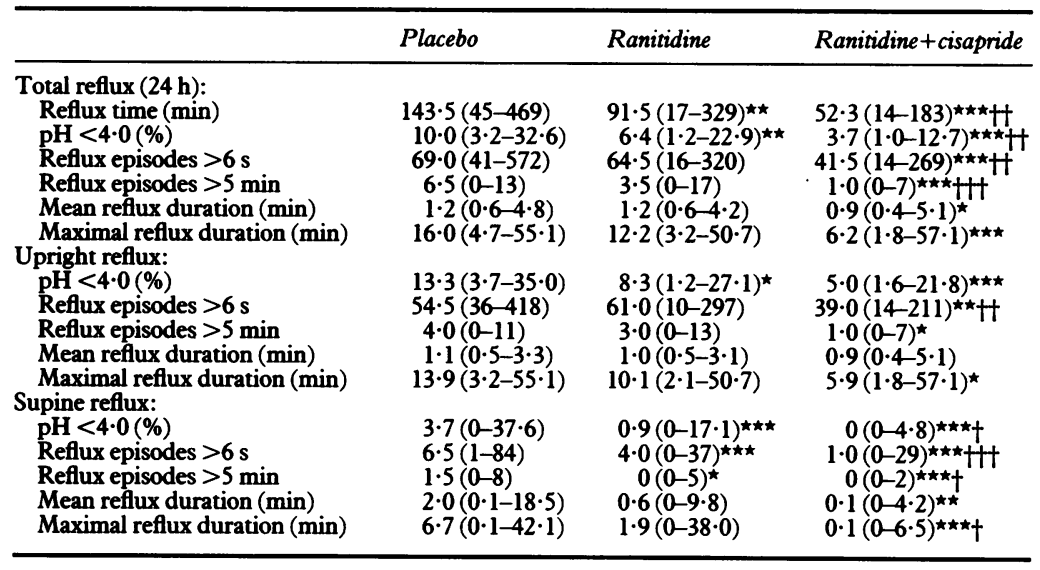

${ }^{\star} \mathrm{p}<0.05 ;{ }^{\star \star} \mathrm{p}<0.01 ;{ }^{\star \star \star} \mathrm{p}<0.001 v$ placebo; $\mathrm{tp}<0.05 ; \mathrm{Hp}<0.01 ; \mathrm{H} \mathrm{p}<0.001 v$ ranitidine; values are median (range); reflux time is only given for 24 hours as duration of uprights and supine periods differed between measurements and patients.

TABLE II Postprandial acid reflux (defined as intraoesophageal $\mathrm{pH}<4 \cdot 0$ ) in 18 patients with erosive reflux oesophagitis

\begin{tabular}{|c|c|c|c|}
\hline & Placebo & Ranitidine & Ranitidine + cisapride \\
\hline \multicolumn{4}{|l|}{ Breakfast: } \\
\hline $\mathrm{pH}<4 \cdot 0(\%)$ & $16 \cdot 1(1 \cdot 5-59 \cdot 5)$ & $0 \cdot 3(0-67 \cdot 2)^{\star \star \star}$ & $0 \cdot 1(0-24 \cdot 7)^{\star \star \star}$ \\
\hline Reflux episodes $>6 \mathrm{~s}$ & $9 \cdot 0(3-58)$ & $1 \cdot 5(0-46)^{\star \star}$ & $0.5(0-39)^{\star \star \star}$ \\
\hline Reflux episodes $>5 \mathrm{~min}$ & $1 \cdot 0(0-5)$ & $0(0-5)^{\star \star \star}$ & $0(0-1) \star \star$ \\
\hline $\begin{array}{l}\text { Mean reflux duration (min) } \\
\text { Maximal reflux duration (min) }\end{array}$ & $1 \cdot 2(0 \cdot 5-23 \cdot 8)$ & $0 \cdot 2(0-3 \cdot 0)^{\star \star \star}$ & $0 \cdot 1(0-4 \cdot 3)^{\star \star \star}$ \\
\hline $\begin{array}{l}\text { Maximal reflux duration (min) } \\
\text { Lunch: }\end{array}$ & $5 \cdot 8(2 \cdot 1-55 \cdot 1)$ & $0 \cdot 2(0-25 \cdot 7)^{\star \star}$ & $0 \cdot 1(0-18 \cdot 6)^{\star \star \star}$ \\
\hline $\begin{array}{l}\text { Lunch: } \\
\text { pH }<4.0(\%)\end{array}$ & $20 \cdot 0(2 \cdot 7-48 \cdot 9)$ & $8 \cdot 8(0 \cdot 2-27 \cdot 0)^{\star \star}$ & $1.9(0-29 \cdot 4)^{\star \star \star} \dagger$ \\
\hline Reflux episodes $>6 \mathrm{~s}$ & $10 \cdot 0(3-56)$ & $7 \cdot 0(1-34)$ & $3.5(0-62) \star \star$ \\
\hline Reflux episodes $>5 \mathrm{~min}$ & $1.0(0-3)$ & $0(0-2)$ & $0(0-1)^{\star}$ \\
\hline Mean reflux duration (min). & $1.4(0.3-14 \cdot 7)$ & $1 \cdot 2(0 \cdot 2-3 \cdot 4)$ & $0.5(0-1 \cdot 0) \star \star \star \dagger$ \\
\hline $\begin{array}{l}\text { Maximal reflux duration (min) } \\
\text { Dinner: }\end{array}$ & $5 \cdot 0(0 \cdot 6-48 \cdot 2)$ & $4 \cdot 4(0 \cdot 2-13 \cdot 0)$ & $1 \cdot 2(0-6 \cdot 0)^{\star \star} \dagger$ \\
\hline $\begin{array}{l}\text { Dinner: } \\
\text { pH }<4.0(\%)\end{array}$ & $15 \cdot 4(2 \cdot 3-49 \cdot 3)$ & $27 \cdot 2(2 \cdot 3-66 \cdot 6)$ & $13 \cdot 5(1 \cdot 2-71 \cdot 0)$ \\
\hline Reflux episodes $>6 \mathrm{~s}$ & $11 \cdot 5(4-79)$ & $18 \cdot 5(5-59)$ & $11 \cdot 0(5-64)$ \\
\hline Reflux episodes $>5 \mathrm{~min}$ & $\begin{array}{l}0.5(0-3) \\
1.6(0.3-6.2)\end{array}$ & $\begin{array}{l}1 \cdot 0(0-3) \\
1 \cdot 4(0 \cdot 2-4 \cdot 0)\end{array}$ & $\begin{array}{l}0(0-5) \\
1 \cdot 1(0-10 \cdot 7)\end{array}$ \\
\hline Maximal reflux duration (min) & $4 \cdot 7(1 \cdot 6-23 \cdot 9)$ & $7 \cdot 4(0 \cdot 6-50 \cdot 7)$ & $4 \cdot 6(0 \cdot 3-57 \cdot 1)$ \\
\hline
\end{tabular}

${ }^{\star} \mathrm{p}<0.05 ;{ }^{\star \star} \mathrm{p}<0.01 ;{ }^{\star \star \star} \mathrm{p}<0.001 v$ placebo; $\mathrm{tp}<0.05 v$ ranitidine; Breakfast, lunch, and dinner were given at 0915,1200 , and 1800; postprandial reflux was analysed between 0945-1145, 1230-1430, and 1830-2030. Values are median (range); $n=18$ for all measures.

\section{STATISTICS}

The results are shown as median (range). For statistical comparison, the non-parametric Wilcoxon signed rank test for paired observations was used. ${ }^{39}$ To avoid multiple testing, only the major variables of interest were analysed that is, for acid reflux: total reflux time, number and duration of reflux episodes; for oesophageal motility: contraction amplitude and duration, area under the curve, propagation velocity, contractility, and number of contractions. $p$ Values $<0.05$ were considered as significant.

\section{Results}

OESOPHAGEAL ACID EXPOSURE

With placebo treatment, the $\mathrm{pH}$ in the distal oesophagus (sensor position $5 \mathrm{~cm}$ above the lower oesophageal sphincter) remained below $4 \cdot 0$ during $10(3 \cdot 2-32 \cdot 6) \%(n=18)$ of the 24 hour recording period (Fig 1). During treatment with ranitidine, reflux time fell to $6.4(1 \cdot 2-22 \cdot 9) \%$ $(\mathrm{p}<0.01 v$ placebo) with a further reduction to $3 \cdot 7(1 \cdot 0-12 \cdot 7) \%(\mathrm{p}<0.001 v$ placebo, $\mathrm{p}<0.01 v$ ranitidine) during treatment with ranitidine plus cisapride.

Upright reflux was more than three times greater than supine reflux $(\mathrm{p}<0.01)$ (Figs 2 (A and B), Table I). Ranitidine reduced both upright and supine reflux and an additional reduction of supine reflux was produced by the combination with cisapride.

The highest values for oesophageal exposure to acid were found during the postprandial periods (Table II). Ranitidine diminished the postprandial reflux found after breakfast and lunch but had no effect on postprandial reflux after dinner. The addition of cisapride led to a further reduction of postprandial reflux after lunch.

Whereas ranitidine only slightly decreased the number and duration of reflux episodes, the combination of ranitidine plus cisapride reduced the number and maximal duration of reflux episodes during the $24 \mathrm{~h}$, upright, supine, and postprandial periods after breakfast and lunch (Fig 3 (A and B), Tables I and II).

\section{OESOPHAGEAL MOTILITY}

Table III shows the various measures of oesophageal contraction, analysed for the entire $24 \mathrm{~h}$ recording period. During placebo, the median amplitude of oesophageal contractions was higher in the proximal than the distal oesophagus (35.0 mm Hg (19-53) v $26.8 \mathrm{~mm} \mathrm{Hg}$ (13-54), $\mathrm{p}<0.05$ ) in the upright period. By contrast, the median amplitude of contraction was higher in the distal than in the proximal oesophagus during the supine period $(33.3 \mathrm{~mm} \mathrm{Hg}(18-71) v$ $29 \mathrm{~mm} \mathrm{Hg}(19-56), \mathrm{p}<0.05)$. Compared with the proximal oesophagus, the median duration of oesophageal contractions $(p<0.05)$ and the median area under the pressure curve $(p<0.05)$ were also higher in the distal oesophagus. The total number and the number of propagated and non-propagated contractions were two to four times higher during the upright than the supine period $(p<0 \cdot 001)$. Propagated contractions were 

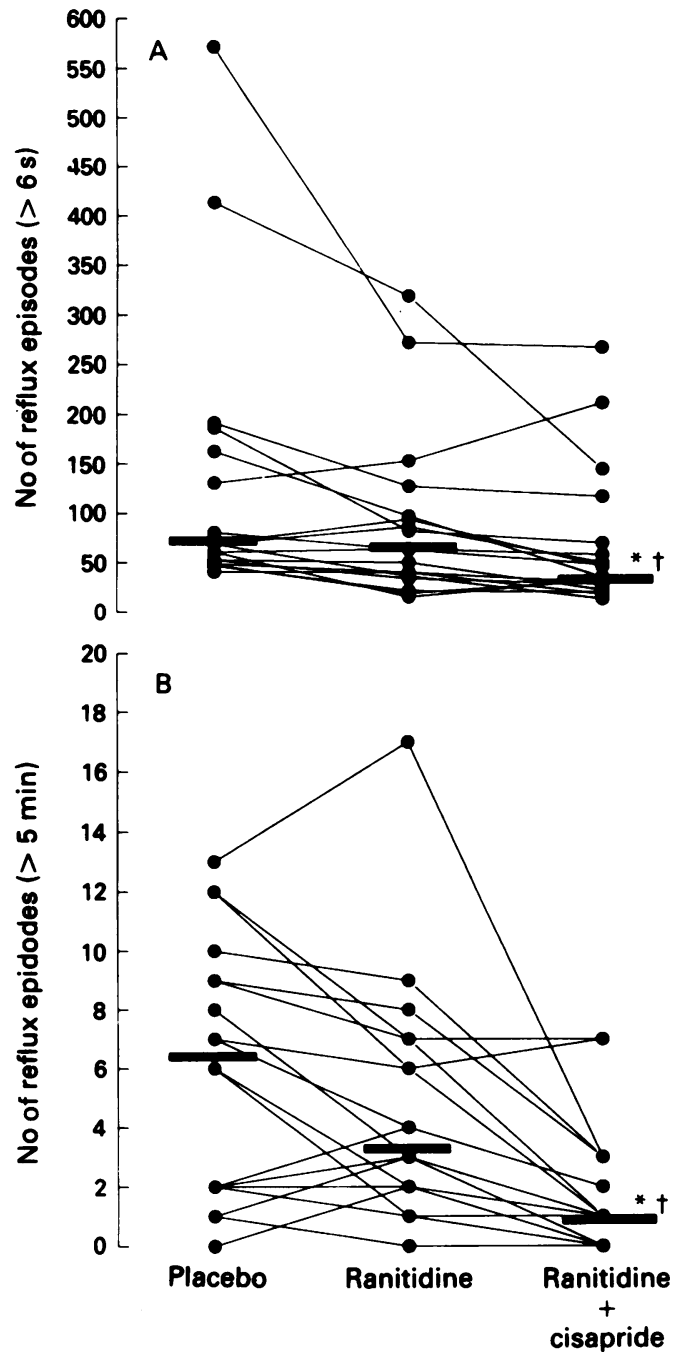

Figure 3: (A) Number of reflux episodes $(>6 s)$. The number of reflux episodes is shown for the entire 24 hour recording period. Horizontal bars indicate median; $n=18$ for all treatments. ${ }^{\star} p<0.001 \mathrm{v}$ placebo; $t p<0.01 \mathrm{v}$ ranitidine. (B) Number of reflux episodes ( $>5$ min). The number of reflux episodes is shown for the entire 24 hour recording period. Horizontal bars indicate median; $n=18$ for all treatments. ${ }^{\star} p<0.001 \mathrm{v}$ placebo; $t p<0.001 \mathrm{v}$ ranitidine.

more often recorded in the proximal oesophagus $(\mathrm{p}<0.05)$, whereas non-propagated contractions occurred about twice as often in the distal as in the proximal oesophagus $(\mathrm{p}<0.001)$.

Ranitidine did not affect oesophageal motility. Compared with ranitidine, the addition of cisapride led to an increase of contraction amplitude during the upright period (from $28 \cdot 0$ (14-54) $\mathrm{mm} \mathrm{Hg}$ to 32.5 (13-56) $\mathrm{mm} \mathrm{Hg}, \mathrm{p}<0.05)$, and the postprandial periods after breakfast (from $27 \cdot 0$ (14-56) $\mathrm{mm} \mathrm{Hg}$ to 33.5 (12-72) $\mathrm{mm} \mathrm{Hg}$, $\mathrm{p}<0.05$ ) and lunch (from $27.9(15-44) \mathrm{mm} \mathrm{Hg}$ to $35.5(19-46) \mathrm{mm} \mathrm{Hg}, \mathrm{p}<0.05)$. During the upright period, cisapride further enhanced the duration of oesophageal contractions (from $3 \cdot 2$ $(2 \cdot 8-4 \cdot 2) \mathrm{s}$ to $3.6(3.0-4 \cdot 4) \mathrm{s}, \mathrm{p}<0.05)$. A cisapride induced increase in the area under the pressure curve was found during the $24 \mathrm{~h}$ period (Table III) and the postprandial periods after breakfast (from $41.6(20-82) \mathrm{mm} \mathrm{Hg} \times \mathrm{s}$ to 55.0 (23-114) $\mathrm{mm} \mathrm{Hg} \times \mathrm{s}, \mathrm{p}<0.05)$ and lunch (from $37.5(21-103) \mathrm{mm} \mathrm{Hg} \times \mathrm{s}$ to $50.5(23-81)$ $\mathrm{mm} \mathrm{Hg} \times \mathrm{s}, \mathrm{p}<0.05)$. These effects of cisapride were confined to the mid and distal oesophagus. Table III shows that cisapride further increased the propagation velocity of oesophageal contractions but had no significant effect on oesophageal contractility (slope of the contraction curve) or on the number of total, propagated, and nonpropagated contractions.

\section{Discussion}

This is the first study presenting 24 hour combined $\mathrm{pH}$ and four channel manometry of the oesophagus in patients with reflux oesophagitis. The most important and novel findings are that the combination of the histamine $\mathrm{H}_{2}$ receptor antagonist ranitidine and the prokinetic agent cisapride greatly reduced oesophageal exposure to acid, and the addition of a standard oral dose of cisapride increased amplitude, duration, and propagation velocity of oesophageal contractions compared with placebo and ranitidine alone.

In our study group of 18 patients who had endoscopically confirmed reflux oesophagitis, we found a total reflux time ranging from $3 \cdot 2 \%$ to $32.6 \%$ in the absence of treatment (Fig 1). Therefore, our patients represent the full range from slight to severe gastro-oesophageal reflux. Sixteen of our 18 patients had combined reflux (reflux occurring in upright and supine positions), a pattern that is closely related to the development of oesophagitis. ${ }^{40}$ The highest reflux values were found during the postprandial periods (Table II). This has been explained by an increased number of transient sphincter relaxations after a meal. ${ }^{3}$

The overall reduction of acid reflux by ranitidine (150 mg twice daily) was about $30 \%$ (Fig 1), which is comparable with the decrease found in other 24 hour oesophageal $\mathrm{pH}$ measurement studies. ${ }^{4142}$ Although ranitidine reduced both daytime (upright) and nocturnal (supine) reflux, it led to a more pronounced decrease of nocturnal reflux. During the postprandial periods, reduction of reflux was most pronounced after breakfast, less pronounced after lunch, and no effect was found after dinner (Table II). These variations reflect the pattern of gastric acid secretion under treatment with ranitidine and are consistent with the studies measuring the effect of ranitidine on 24 hour intragastric acidity in patients with reflux oesophagitis. ${ }^{434}$

Four channel manometry of the oesophagus with sensors located at $20,15,10$, and $5 \mathrm{~cm}$ above the lower oesophageal sphincter permits analysis of contraction characteristics for different parts of the tubular oesophagus. With placebo treatment, the duration of contraction was higher in the distal oesophagus, a finding that confirms earlier studies in healthy volunteers. ${ }^{37456}$ During the upright period, contraction amplitude was higher in the proximal than the distal oesophagus, which contrasts with healthy volunteers ${ }^{45}$ and may indicate a reduced contractile force of the distal oesophagus and thus impaired acid clearing in patients with reflux oesophagitis. The addition of cisapride led to a significant increase of median contraction amplitude and duration, but only in the mid and distal oesophagus. This may be explained by the selective cholinomimetic action of cisapride on the smooth muscle in the mid and distal oesophagus whereas the striated muscle of the proximal 
TABLE III Oesophageal motility $(24 h)$ in 18 patients with erosive reflux oesophagitis

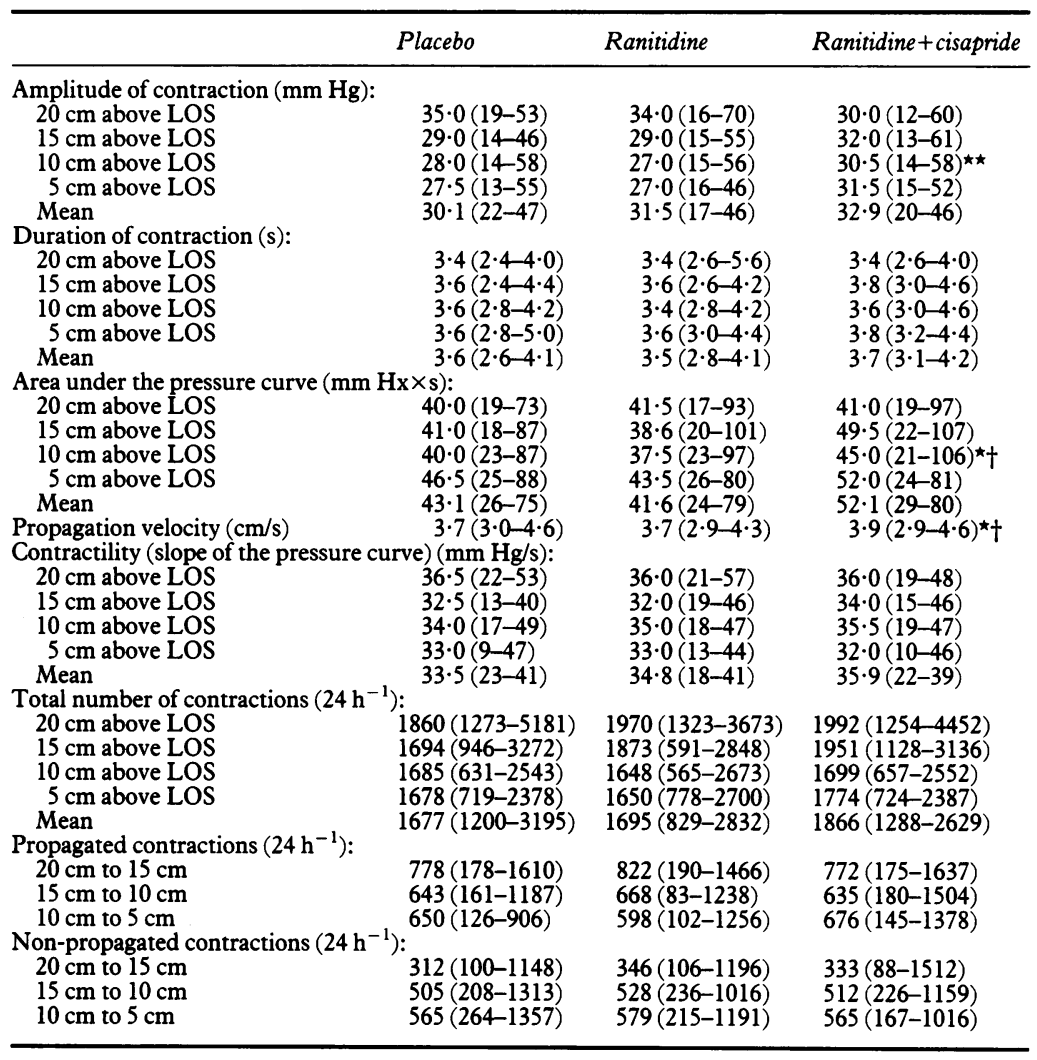

${ }^{\star} \mathrm{p}<0.05 ;{ }^{\star \star} \mathrm{p}<0.01 v$ placebo; $\mathrm{tp}<0.01 v$ placebo. Oesophageal body motility was analysed for the entire 24 hour period; values are shown as median (range); $\mathrm{n}=18$ for all measures; $\mathrm{cm}$ above $\mathrm{LOS}=$ sensor position above the lower oesophageal sphincter; mean=arithmetic mean of median values obtained for each sensor. two channel manometry should therefore be used for reliable recording of oesophageal motility.

As expected, contraction frequency was considerably higher during the day. Propagated contractions, which are thought to be predominantly under voluntary control, were detected more often in the proximal oesophagus whereas non-propagated contractions prevailed in the mid and distal oesophagus. It has been suggested that the distal non-propagated contractions are incomplete secondary contractions induced by gastro-oesophageal reflux. The finding that their number is neither affected by ranitidine nor by cisapride treatment does not support this hypothesis.

Although the combination of cisapride and ranitidine significantly increased amplitude, duration, and propagation velocity of oesophageal contractions, the changes in oesophageal motility seem small when compared with the considerable reduction in acid reflux. Therefore additional effects of cisapride on gastro-oesophageal motility such as an improvement of lower oesophageal sphincter function ${ }^{48} 49$ and an acceleration of gastric emptying ${ }^{18}$ might contribute to the reduction in acid reflux. On the other hand, the increase found in the contractile force of the oesophageal body together with an accelerated propagation of the contraction waves may be responsible for the acceleration of acid clearance.

In conclusion, the combination of cisapride with ranitidine leads to a considerable and additional reduction in oesophageal acid exposure compared with that achieved by ranitidine alone. Combined treatment with a histamine $\mathrm{H}_{2}$ receptor antagonist such as ranitidine and a prokinetic agent such as cisapride is a promising alternative for medical treatment of reflux oesophagitis and should be further tested in clinical trials. We acknowledge the invaluable technical help of Dr Joachim
Gross, PhD, Medical Instruments Corporation, Solothurn, Gross, PhD, Medical Instruments Corporation, Solothurn, Switzerland. We are also grateful to Dr Josef Geissbühler,
Medizinische Abteilung, Regionalspital Langenthal, SwitzerMedizinische Abteilung, Regionalspital Langenthal, Switzer-
land who provided five patients. We acknowledge the secretarial land who provided five patients. We acknowledge the secretarial help of Kathrin Inauen. The study was supported by a research grant for Glaxo Group Research, Greenford, England. Additional
funds were from the Swiss National Science Foundation (3226369.89) and Deutsche Forschungsgemeinschaft (Em 36-2/1) The study was presented in part to the American Gastroenterological Association (May 1992) and has been published as an abstract (Gastroenterology 1992; 102: A86).

1 Tytgat GNJ, Nio CY, Schotborgh RH. Reflux esophagitis Scand $\mathcal{F}$ Gastroenterol 1990; 25 (suppl 175): 1-12.

2 Dodds WJ, Hogan WJ, Helm JF, Dent J. Pathogenesis of reflux esophagitis. Gastroenterology $1981 ; 81$ : 376-94.

3 Dodds WJ, Dent J, Hogan WJ, Helm JF, Hauser R, Patel GK, et al. Mechanisms of gastroesophageal reflux in patients

4 Katz PO, Knuff TE, Benjamin SB, Castell DO. Mechanism of gastroesophageal reflux in patients with reflux esophagitis. Am F Gastroenterol 1986; 81: 744-6.

5 Kahrilas PJ, Dodds WJ, Hogan WJ, Kern M, Arndorfer RC, Reece A. Esophageal peristaltic dysfunction in peptic esophagitis. Gastroenterology 1986; 91: 897-904.

6 Gill RC, Bowes KL, Murphy PD, Kingma YJ. Esophageal motor abnormalities in gastroesophageal reflux and the effects of fundoplication. Gastroenterology 1986; 91: 364-9.

7 Baldi F, Ferrarini F, Longanesi A, Angeloni M, Ragazzini M Miglioli $M$, et al. Oesophageal function before, during, and after healing of erosive esophagitis. Gut 1988; 29: 157-60.

8 Dent J, Dodds WJ, Friedman RH, Sekiguchi T, Hogan WJ, Arndorfer RC, et al. Mechanism of gastroesophageal reflux in recumbent asymptomatic human subjects. $\mathcal{F}$ Clin Invest in recumbent asymp

9 Holloway RH, Hongo M, Berger K, McCallum RW. Gastric distension: a mechanism for postprandial gastroesophageal reflux. Gastroenterology 1985; 89: 779-84. 
10 Hillemeier AC, Grill BB, McCallum RW, Gryboski J Esophageal and gastric motor abnormalities in gastro-
esophageal reflux during infancy. Gastroenterology 1983; 84: esophagea $741-6$.

11 Baldi F, Ferrarini F, Balestra R, Borioni D, Longanesi A, Miglioli $M$, et al. Oesophageal motor events at the occurrence of acid reflux and during endogenous acid exposure in healthy subjects and in patients with oesophagitis. Gut 1985; 26: $336-41$.

12 Eriksen CA, Sadek SA, Cranford C, Sutton D, Kennedy N, Cuschieri A. Reflux oesophagitis and oesophageal transit: evidence for a primary oesophageal motor disorder. Gut 1988; 29: 448-52.

13 McCallum RW, Berkowitz DM, Lerner E. Gastric emptying in patients with gastroesophageal reflux. Gastroenterology in patients with
$1981 ; 80: 285-91$

14 McCallum RW, Fink SM, Lerner E, Berkowitz DM. Effects of metoclopramide and bethanechol on delayed gastric
emptying present in gastroesophageal reflux patients. emptying present in gastroesoph

15 Behar J, Ramsby G. Gastric emptying and antral motility in reflux esophagitis. Effect of oral metoclopramide. Gastroenterology 1978; 74: 253-6.

16 Shay SS, Eggli D, McDonald C, Johnson LF. Gastric emptying of solid food in patients with gastroesophageal reflux. Gastroenterology 1987; 92: 459-65.

17 Keshavarzian A, Bushnell DL, Sontag S, Yegelwel EJ, Smid $K$. Gastric emptying in patients with severe reflux esophagitis. Am f Gastroenterol 1991; 86: 738-42.

18 Maddern GJ, Jamieson GG, Myers JC, Collins PJ. Effect of cisapride on delayed gastric emptying in gastro-oesophageal reflux disease. Gut $1991 ; 32: 470-4$.

19 Koelz HR, Birchler R, Bretholz A, Bron B, Capitaine Y, Delmore G, et al. Healing and relapse of reflux esophagitis during treatment with ranitidine. Gastroenterology 1986; 91: 1198-205.

20 Havelund T, Laursen LS, Skoubo-Kristensen E, Andersen BN, Pedersen SA, Jensen KB, et al. Omeprazole and ranitidine in treatment of reflux oesophagitis: double blind comparative trial. $B M \mathcal{F}$ 1988; 296: 89-92.

21 Lundell L, Backman L, Ekström P, Enander Lk, Falkmer S, Fausa $\mathrm{O}$, et al. Prevention of relapse of reflux esophagitis after endoscopic healing: the efficacy and safety of omeprazole compared with ranitidine. Scand $\mathcal{F}$ Gastroenterol 1991; 26: $248-56$.

22 Verlinden M. Review article: a role for gastrointestinal prokinetic agents in the treatment of reflux oesophagitis? kinetic agents in the treatment of reflux
Aliment Pharmacol Therap 1989; 3: 113-31.

23 Baldi F, Bianchi Porro G, Dobrilla G, Iascone C, Lobello R, Marzio $\mathrm{L}$, et al. Cisapride versus placebo in reflux esophagitis. A multicenter double-blind trial. $\mathcal{f}$ Clin Gastroenterol 1988; 10: 614-8

24 Lepoutre L, Van Der Spek P, Vanderlinden I, Bollen J, Laukens P. Healing of grade-II and III esophagitis through motility stimulation with cisapride. Digestion 1990; 45: 10914.

25 Janisch HD, Hüttemann W, Bouzo MH. Cisapride versus ranitidine in the treatment of reflux esophagitis. Hepatoranitidine in the treatment of
gastroenterology $1988 ; 35: 125-7$.

26 Galmiche JP, Fraitag B, Filoche B, Evreux M, Vitaux J, Zeitoun $\mathrm{P}$, et al. Double-blind comparison of cisapride and cimetidine in treatment of reflux esophagitis. Dig Dis $S c i$ 1990; 35: 649-55.

27 Maleev A, Mendizova A, Popov P, Vlahov V, Dimitrov B, Mihova A, et al. Cisapride and cimetidine in the treatment of erosive esophagitis. Hepatogastroenterology 1990; 37: 403-7.

28 Toussaint J, Gossuin A, Deruyttere M, Hublé F, Devis G Healing and prevention of relapse of reflux oesophagitis by cisapride. Gut 1991; 32: 1280-5.

29 Bumm R, Emde C, Armstrong D, Bauerfeind P, Blum AL. Ambulatory esophageal manometry: comparison of expert and computer-aided analyses. Fournal Gastrointestinal Motility 1990; 2: 216-23.

30 Wiener GJ, Morgan TM, Copper JB, Wu WC, Castell DO Sinclair JW, et al. Ambulatory 24-hour esophageal pH monitoring. Reproducibility and variability of $\mathrm{pH}$ parameters. Dig Dis Sci 1988; 33: 1127-33.

31 Johnsson F, Joelsson B. Reproducibility of ambulatory oesophageal pH monitoring. Gut 1988; 29: 886-9.

32 Emde C, Armstrong D, Blum AL. Computer-assisted ambulatory long-term manometry of tubular esophagus. Dig Dis Sci 1991; 36: 90S-7S.

33 Emde C, Armstrong D, Castiglione F, Cilluffo T, Riecken EO, Blum AL. Reproducibility of long-term ambulatory esophageal combined $\mathrm{pH} / \mathrm{manometry}$ Gastroenterology 1991; 100: 1630-7.

34 Savary M, Miller G. L'oesophage. Manuel et atlas d'endoscopie. Solothurn, Switzerland: Gassmann AG, 1977.

35 Tytgat GNJ, Bennett JR, Dent J, Joelsson B. Oesophageal pH monitoring - normal and abnormal. Gastroenterology Intermonitoring - normal and $1989 ; 2$ : 141-9.

36 Emde C, Armstrong D, Bumm R, Kaufhold HJ, Riecken EO, Blum AL. Twenty-four hour continuous ambulatory measurement of oesophageal $\mathrm{pH}$ and pressure: a digital recording system and computer-aided manometry analysis. fournal Ambulatory Monitoring 1990; 3: 47-62.

37 Armstrong D, Emde C, Bumm R, Castiglione F, Cilluffo T, Blum AL. Twenty-four-hour pattern of esophageal motility in asymptomatic volunteers. Dig Dis Sci 1990; 35: 1190-7.

38 Johnson LF, DeMeester TR. Twenty-four-hour pH monitoring of the distal esophagus. A quantitative measure of gastroesophageal reflux. Am $\mathcal{F}$ Gastroenterol 1974; 62: 32532 .

39 Keppel G. Design and analysis. A researcher's handbook. 2nd ed. Englewood Cliffs, New Jersey: Prentice Hall, 1982.

40 De Caestecker JS, Blackwell JN, Pryde A, Heading RC. Daytime gastro-oesophageal reflux is important in oesophagitis. Gut 1987; 28: 519-26.

41 Johansson KE, Tibbling L. Gastric secretion and reflux pattern in reflux oesophagitis before and during ranitidine treatment. Scand F Gastroenterol 1986; 21: 487-92.

42 Klinkenberg-Knol EC, Festen HPM, Meuwissen SGM. The effects of omeprazole and ranitidine on 24-hour $\mathrm{pH}$ in the distal oesophagus of patients with reflux oesophagitis. Aliment Pharmacol Therap 1988; 2: 221-7.

43 Mahachai V, Walker $\mathrm{K}$, Thomson ABR. Comparison of cimetidine and ranitidine on 24-hour intragastric acidity and serum gastrin profile in patients with esophagitis. Dig Dis Sci serum gastrin profil

44 Lind T, Cederberg C, Idstrom JP. Lonroth H, Olbe L, Lundell L. 24-hour intragastric acidity and plasma gastrin during long-term treatment with omeprazole or ranitidine in patients with reflux esophagitis. Scand $\mathcal{F}$ Gastroenterol 1991; 26: $620-6$.

45 Richter JE, Wu WC, Johns DN, Blackwell JN, Nelson JL Castell JA, et al. Esophageal manometry in 95 healthy adul volunteers. Variability of pressures with age and frequency
of 'abnormal' contractions. Dig Dis Sci 1987; 32: 583-92.

46 Smout AJPM, Breedijk M, Van der Zouw C, Akkerman LMA. Physiological gastroesophageal reflux and esophageal motor activity studied with a new system for 24-hour recording and automated analysis. Dig Dis Sci 1989; 34: recording

47 Gilbert RJ, Dodds WJ, Kahrilas PJ, Hogan WJ, Lipman S. Effect of cisapride, a new prokinetic agent on esophageal motor function. Dig Dis Sci 1987; 32: 1331-6.

48 Ceccatelli P, Janssens J, Vantrappen G, Cucchiara S. Cisapride restores the decreased lower oesophageal sphincter pressure in reflux patients. Gut 1988; 29: 631-5.

49 Corazziari E, Bontempo I, Anzini F. Effects of cisapride on distal esophageal motility in humans. Dig Dis Sci 1989; 34: $1600-5$.

50 Holloway RH, Downton J, Mitchell B, Dent J. Effect of cisapride on postprandial gastro-oesophageal reflux. Gut 1989; 30: 1187-93.

51 Inauen W, Emde C, Weber B, Armstrong D, Bettschen HU, Huber $\mathrm{T}$, et al. Cisapride increases esophageal propagation velocity in patients with reflux esophagitis: A 24-h manometric study comparing 4-vs. 2-channel recordings [Abstract]. Endoscopy 1992; 24: 626-7. 